\title{
The affect distance analysis of tunnel blasting vibration on adjacent buildings
}

\author{
Hui Wang ${ }^{1}$ a , Cai Xu² and Xuerui Yang ${ }^{1}$, \\ ${ }^{1}$ Guizhou Construction Science Research \& Desigh Institute Co. Ltd, Guiyang 550000, China \\ ${ }^{2}$ Zunyi construction (group) coLTD ,Zunyi, 553000, China
}

\begin{abstract}
In the formation of the blasting seismic wave transmission is a complex mechanical process. Blasting seismic wave in different geological structure formation of the interface, diffraction, reflection, projection as the incident Angle is different, all kinds of waveform transformation, formation of different types, different amplitude, frequency and phase of various wave superimposition of random composite wave. Blasting seismic wave propagation distance (horizontal distance and height difference), and the performance of the explosive, explosive charge, charge structure, priming method, congestion state what international airport, the plane and direction, topography and geological conditions will affect the blasting vibration effect. In engineering by empirical formula to estimate main parameters of blasting seismic wave and the structure of the empirical formula is the result of the use of theoretical analysis, by blasting of similar rate to determine the parameters in the formula is made up of many engineering measured data from statistical analysis, or directly by the measured parameters of the blasting seismic wave is given. In this paper, through various points were set in the prison line large speed is the most value, using the mathematical statistics regression analysis method, attenuation coefficient is obtained, and then back to the formula of single ring allows maximum dose safety distance calculated.
\end{abstract}

\section{Project Overview}

A tunnel construction, the villagers reflect negatively with the vibration caused by blasting construction building, blasting excavation exposed rock is gray. Blasting area near a small building height is relatively high, most of the building elevation the blasting area is low, most of the houses have been built for brick structure since. 3 times of field vibration test were conducted on site.

\section{The test is introduced}

For scientific, fair and accurate judgment unit during blasting explosion scope of blasting vibration effect and the influence degree, must be based on the blasting site terrain and geological conditions, find out the blasting vibration wave attenuation law. I center analysis and judgement method is to use the blasting vibration is to actually test of blasting operation, by testing the ground points of different distance from the blasting vibration velocity, blasting vibration intensity analysis, obtained the attenuation law of explosion wave, to provide a scientific basis for reasonable determine a safe distance.

The implementation of blasting vibration test the chengdu zhongke measurement and control co., LTD. Of TC - 4850 type of blasting vibration. TC - 4850 type of blasting vibration is to speed speed sensor, with three sensors placed in the test point, blasting the instrument set to automatically trigger condition, when triggered, the instrument

a1638553132@qq.com

(C) The Authors, published by EDP Sciences. This is an open access article distributed under the terms of the Creative Commons Attribution License 4.0 (http://creativecommons.org/licenses/by/4.0/). 
automatically start recording, the sensor by blasting vibration produced by automatic storage after analog signals to digital conversion. Through the instrument interface connected to the computer by special software for data analysis after processing vibration parameters is given.

\section{The test results}

According to the actual situation, considering the influence of different direction and geological conditions change, the three tests were conducted and the arrangement of measuring points are valid at the time of blasting, three test results are as follows .

Table 1 test results for the first time

\begin{tabular}{|c|c|c|c|c|}
\hline \multirow{2}{*}{$\begin{array}{r}\text { result } \\
\text { point }\end{array}$} & \multicolumn{2}{|c|}{ Channel X } & \multirow{2}{*}{$\begin{array}{c}\text { biggestsingle } \\
\text { ring dose } \\
(\mathbf{k g})\end{array}$} & \multirow{2}{*}{$\begin{array}{c}\text { distance } \\
(\mathbf{m})\end{array}$} \\
\hline & $\begin{array}{c}\text { maximum } \\
(\mathrm{cm} / \mathrm{s})\end{array}$ & $\begin{array}{l}\text { Half wave } \\
\text { frequency }\end{array}$ & & \\
\hline 1 & 0.06 & 36.70 & \multirow{17}{*}{14.0} & 296.27 \\
\hline 2 & 0.07 & 25.89 & & 255.94 \\
\hline 3 & 0.04 & 32.13 & & 383.06 \\
\hline 4 & 0.04 & 40.00 & & 431.82 \\
\hline 5 & 0.07 & 16.81 & & 371.00 \\
\hline & \multicolumn{2}{|c|}{ Channel Y } & & 1 \\
\hline 1 & 0.07 & 32.92 & & 296.27 \\
\hline 2 & 0.09 & 20.30 & & 255.94 \\
\hline 3 & 0.08 & 32.92 & & 383.06 \\
\hline 4 & 0.09 & 35.24 & & 431.82 \\
\hline \multirow[t]{2}{*}{5} & 0.08 & 44.44 & & 371.00 \\
\hline & \multicolumn{2}{|c|}{ Channel Z } & & 1 \\
\hline 1 & 0.14 & 60.15 & & 296.27 \\
\hline 2 & 0.01 & 23.32 & & 255.94 \\
\hline 3 & 0.09 & 36.36 & & 383.06 \\
\hline 4 & 0.08 & 55.17 & & 431.82 \\
\hline 5 & 0.10 & 51.95 & & 371.00 \\
\hline
\end{tabular}

Table 2 test results for the second time

\begin{tabular}{|c|c|c|c|c|}
\hline \multirow{2}{*}{$\begin{array}{l}\text { result } \\
\text { point }\end{array}$} & \multicolumn{2}{|c|}{ Channel X } & \multirow{2}{*}{$\begin{array}{c}\text { biggestsingle } \\
\text { ring dose } \\
(\mathrm{kg})\end{array}$} & \multirow[b]{2}{*}{$\begin{array}{c}\text { distance } \\
(\mathbf{m})\end{array}$} \\
\hline & $\begin{array}{c}\text { maximum } \\
(\mathbf{c m} / \mathbf{s})\end{array}$ & $\begin{array}{c}\text { Half wave } \\
\text { frequency } \\
\text { Hz }\end{array}$ & & \\
\hline 1 & 1.24 & 45.98 & \multirow{20}{*}{14.4} & 54.0 \\
\hline 2 & 0.38 & 46.51 & & 100.0 \\
\hline 3 & 0.13 & 47.62 & & 150.0 \\
\hline 4 & 0.55 & 72.73. & & 24.0 \\
\hline 5 & 0.55 & 33.06 & & 51.0 \\
\hline 6 & 0.89 & 22.60 & & 75.0 \\
\hline & \multicolumn{2}{|c|}{ Channel Y } & & 1 \\
\hline 1 & 1.72 & 31.75 & & 54.0 \\
\hline 2 & 0.44 & 50.63 & & 100.0 \\
\hline 3 & 0.13 & 52.63 & & 150.0 \\
\hline 4 & 0.68 & 32.26 & & 24.0 \\
\hline 5 & 0.75 & 24.84 & & 51.0 \\
\hline \multirow[t]{2}{*}{6} & 0.44 & 21.28 & & 75.0 \\
\hline & \multicolumn{2}{|c|}{ Channel Z } & & 1 \\
\hline 1 & 2.67 & 55.56 & & 54.0 \\
\hline 2 & 0.67 & 60.61 & & 100.0 \\
\hline 3 & 0.21 & 51.95 & & 150.0 \\
\hline 4 & 0.67 & 64.52 & & 24.0 \\
\hline 5 & 0.77 & 68.97 & & 51.0 \\
\hline 6 & 0.93 & 42.11 & & 75.0 \\
\hline
\end{tabular}

Table 3 test results for the third time

\begin{tabular}{|c|c|c|c|c|}
\hline \multirow{2}{*}{$\begin{array}{r}\text { result } \\
\text { point }\end{array}$} & \multicolumn{2}{|c|}{ Channel X } & \multirow{2}{*}{$\begin{array}{c}\text { biggestsingle } \\
\text { ring dose } \\
(\mathrm{kg})\end{array}$} & \multirow[b]{2}{*}{$\begin{array}{c}\text { distance } \\
\text { (m) }\end{array}$} \\
\hline & $\begin{array}{c}\text { maximum } \\
(\mathrm{cm} / \mathrm{s})\end{array}$ & $\begin{array}{c}\text { Half wave } \\
\text { frequency } \\
\mathbf{H z} \\
\end{array}$ & & \\
\hline 1 & 1.09 & 8.32 & \multirow{2}{*}{14.0} & 56.0 \\
\hline 2 & 0.11 & 54.79 & & 81.0 \\
\hline
\end{tabular}




\begin{tabular}{|c|c|c|c|}
\hline 3 & 0.19 & 250.00 & 106.0 \\
\hline 4 & 0.13 & 63.49 & 131.0 \\
\hline 5 & 0.16 & 60.61 & 156.0 \\
\hline 6 & 0.38 & 59.70 & 181.0 \\
\hline & \multicolumn{2}{|c|}{ Channel Y } & \\
\hline 1 & 0.62 & 61.54 & 56.0 \\
\hline 2 & 0.13 & 60.61 & 81.0 \\
\hline 3 & 0.58 & 85.11 & 106.0 \\
\hline 4 & 0.11 & 54.05 & 131.0 \\
\hline 5 & 0.25 & 95.24 & 156.0 \\
\hline \multirow[t]{2}{*}{6} & 0.35 & 60.61 & 181.0 \\
\hline & \multicolumn{2}{|c|}{ Channel Z } & \\
\hline 1 & 1.11 & 65.57 & 56.0 \\
\hline 2 & 0.21 & 50.63 & 81.0 \\
\hline 3 & 0.34 & 266.67 & 106.0 \\
\hline 4 & 0.16 & 74.07 & 131.0 \\
\hline 5 & 0.22 & 58.82 & 156.0 \\
\hline 6 & 0.53 & 60.61 & 181.0 \\
\hline
\end{tabular}

\section{Regression analysis to test results}

By 《safety regulations for blasting $》(\mathrm{~GB} 6722-2003)$ was 6.2. 3

$$
\text { Type } \quad R=\left(\frac{K}{V}\right)^{\frac{1}{a}} \cdot Q^{\frac{1}{3}}
$$

$R$-Blasting vibration safety allows the distance, the unit is $(\mathrm{m})$;

$Q$-Dynamite, simultaneous blasting for total dosage, time delay blasting is a maximum dosage, the unit is $(\mathrm{kg})$;

$V$-Allowed to defend the security of object location of particle velocity, the unit is $\mathrm{cm}$ per second $(\mathrm{cm} / \mathrm{s})$;

$K$ 、 a -Protection object and break point to calculate the terrain, geological conditions of related coefficient and the attenuation index, can according to the 《blasting safety regulations 》(GB6722-2003) [1] 43 selection table on page 5 , or determined by field test. Blasting industry [2-5] many scholars in different topographic and geological conditions The size of the value and its change law, discussed a lot, in addition to a certain rule. But the author thinks that should be adopted by the field test of regression analysis to determine the two values. Will be in style

$$
\rho=Q^{1 / 3} / R
$$

Command $y=\ln V, x=\ln \rho, m=\ln K, n=\alpha$

$$
\text { (1) can be } y=m+n x
$$

Organizing, test data and draw curve as shown in figure 1: the figure in the linear regression curve, can be obtained, $\mathrm{n}=1.060, \mathrm{~m}=3.070$ 。

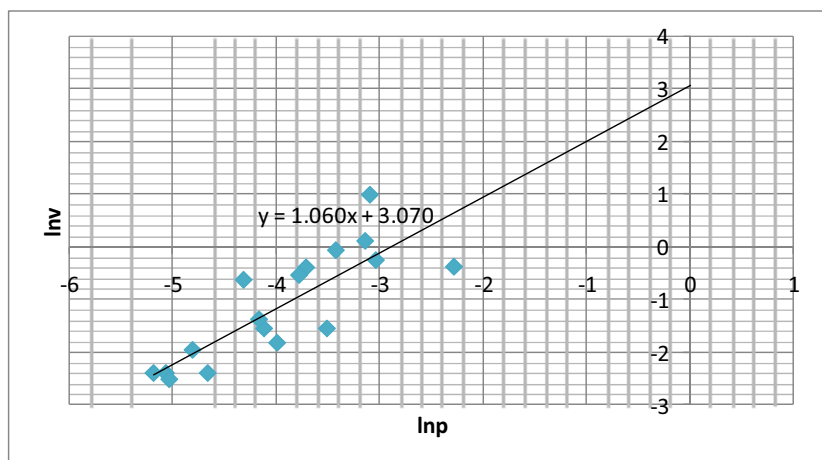

Figure 1. Test regression curve regression curve

To be on the safe side, $n$ values, the curve move up (see $f$ igure 2), so that you can include all points of $\mathrm{m} \mathrm{m}$ value $\max$ imum, is obtained $\mathrm{m}=4.27$ 。

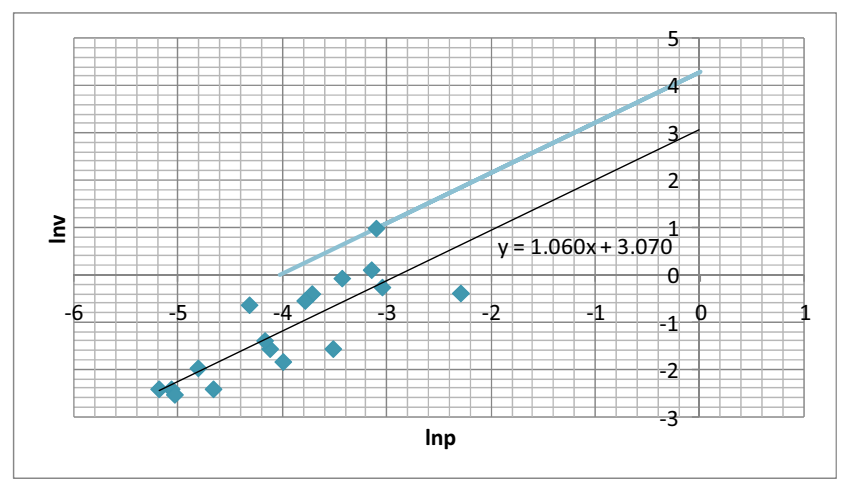

Figure 2 Test the envelope

Then, $\mathrm{K}=\mathrm{em}=71 \cdot 52, \mathrm{n}=\mathrm{a}=1.06$. According to the The blasting safety procedurField test basic vibration frequency is greater 
than $10 \mathrm{HzBasic}$ and local premises is generally brick, non seismic large block buildings, so take safety vibration velocity for $2.3 \mathrm{~cm} / \mathrm{s}$ The distance formula (1) a

$$
R=\left(\frac{71.52}{2.3}\right)^{\frac{1}{1.06}} \cdot Q^{\frac{1}{3}}
$$

\section{Conclusion}

1) Because of the influence of different geological conditions of blasting vibration, such as $\mathrm{k}$ 、 a coefficient should be determined by field test;

2) Proposed to ensure the safety of the housing $m$ value is used in this paper, the testing method of envelope, make its can include a maximum of all $\mathrm{m}$;

3) Should be carried out prior to the tunnel construction blasting vibration testing and related parameters, formulate reasonable blasting construction scheme, quality by holes or differential [J]. blasting,200825 (3); 96-99. blasting method, control the largest single dose, control harmful blasting vibration effect.

\section{References}

[1] 《The blasting safety procedures》 GB6722-2003 [S]; [2]Tao Lv.Hai bo Li, etc Spread the influence of the dielectric characteristics of blasting vibration attenuation law [J]Journal of disaster prevention and mitigation ofe ngineering.2008, 28 (3): 337-341;

[3]Yong quan.Liliang $\mathrm{Wu}$.The three gorges underground powerhouse excavation blasting vibration attenuation law research[J] engineering blasting2009, 15 (2): 7-11;

[4] ]Tao Lv.Yongqiang Shi.Cheng Huang.etc. The method of nonlinear regression to blasting vibration velocity attenuation formula parameters $[\mathrm{J}]$ Rock and soil mechanics, 2007, 28 (9) 1871-1878;

[5] Xianlin liu. Chuanbo Zhou.Guosheng Zhang. Tunnel excavation blasting vibration monitoring and vibration velocity prediction analysis 